\title{
Early and late components in the human anal reflex
}

\author{
M SWASH \\ From The London Hospital, Whitechapel, London, UK
}

SUMMARY Perianal electrical stimulation induces reflex activity in the superficial part of the external anal sphincter muscle. Several components of differing latency can be recognised. It is suggested that these correspond with the ripples of contraction observed clinically after perianal scratch stimuli. Some of our earlier studies suggested an erroneously short latency for the first component of this cutaneously-elicited reflex. The reasons for this are discussed.

The anal reflex is usually elicited by pricking or scratching the perianal skin. After a brief delay a flicker of contraction in the superficial part of the external anal sphincter muscle is observed on the side stimulated and, to a lesser degree, on the opposite side. Rossolimo' localised the anal reflex to the sacral segments of the spinal cord and more recent clinical and anatomical studies have suggested that the fourth sacral segments are particularly important. ${ }^{2}$ The anal reflex is absent in lesions of the cauda equina and it is also often absent in patients with idiopathic faecal incontinence. ${ }^{3}$ We have studied the latency of the anal reflex, recorded by an electrophysiological technique, ${ }^{45}$ in patients with idiopathic faecal incontinence, as part of our histopathological ${ }^{67}$ and physiological ${ }^{8-10}$ investigations of this problem. In our studies of normal subjects we have recorded a much shorter latency than that described by Pedersen and colleagues. ${ }^{11}$ Like other cutaneously-elicited reflexes, for example the blink reflex, ${ }^{12}$ the anal reflex probably consists of oligosynaptic and polysynaptic components of short and long latency, respectively. ${ }^{12-14}$ In this report the various components of the anal reflex recorded by our technique ${ }^{45}$ in a group of normal subjects are described, and the differences between our results and those of Pedersen $e t a^{11}$ are discussed. The latencies of the first component of this response are very short and various reasons for this are considered.

\section{Methods}

The anal reflex was elicited in the manner described previ-

Address for reprint requests: $\mathrm{Dr} M$ Swash, The London Hospital, London E1 1BB, UK.

Received 10 February 1982 and in revised form 28 April 1982. Accepted 5 May 1982 ously. ${ }^{4}$ The patient was placed in the left lateral position and a ground electrode was strapped to the dependent thigh. A standard concentric needle EMG electrode was inserted, without anaesthesia, into the superficial portion of the external anal sphincter complex in the midline, $1 \mathrm{~cm}$ posterior to the anal verge. The perianal skin, $1 \mathrm{~cm}$ to $2 \mathrm{~cm}$ from the anus, was stimulated supramaximally (usually with a stimulus of about $90 \mathrm{~V}$ and $0.1 \mathrm{~ms}$ duration) with a bipolar surface stimulating electrode, and the reflex response recorded by the concentric needle EMG electrode was displayed on the oscilloscope of a standard EMG apparatus (Medelec EMG MS6). Stimuli were applied at a rate of $1 \mathrm{~Hz}$. Using the storage mode of the oscilloscope it was then possible to distinguish the reflex response from random basal action potentials ${ }^{59}$ by its larger size, and by its constant latency (fig 1). The latency of the reflex response was measured from the stimulus to the first deflection of the reflex muscle action potential complex (fig 1). The latency of the first component decreases slightly with repeated stimuli and with increasing stimulus voltage and care was therefore taken to allow the latency to stabilise at the shortest value obtainable, before recordings were made, by suitable adjustment of the stimulus. Recordings of the anal latency in which the oscilloscope sweep occupied $50 \mathrm{~ms}$ or more were available in 27 of the larger group of normal subjects in whom we have studied this reflex. Most of these subjects were clinically normal relatives of patients referred for treatment of ano-rectal incontinence and all gave their informed consent for the recordings to be made. In these recordings late components were accepted if they appeared synchronously in all of the five consecutive traces made during each study, if they appeared more than $5 \mathrm{~ms}$ after the cessation of the initial complex of EMG activity in the anal sphincter muscle, and if they resembled the initial action potential complex in form and amplitude (fig 1).

\section{Results}

The latency of the first component of the anal reflex ranged from 6 to $13 \mathrm{~ms}$ (mean $9.3 \pm 2.53 \mathrm{~ms}$ ). A second component was identified in each of these 27 recordings. This second component followed the 


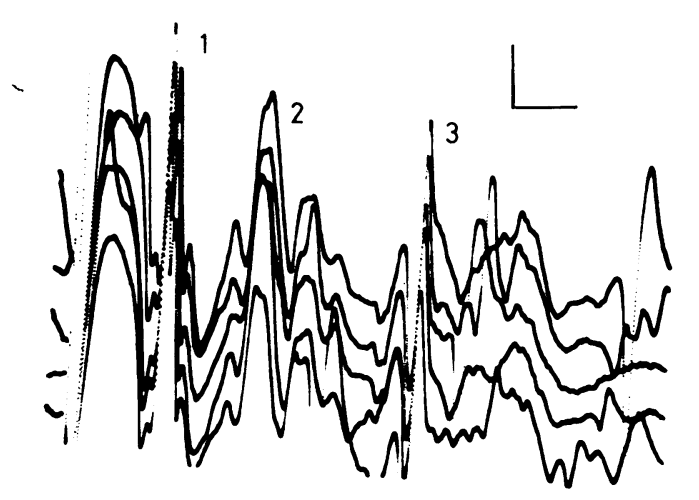

Fig 1 Anal reflex recording calibration $5 \mathrm{~ms}, 100 \mathrm{mV}$. Three components (labelled 1, 2, 3) can be recognised.

first component after an interval of 15 to $33 \mathrm{~ms}$ (mean $23.9 \pm 4.78 \mathrm{~ms}$ ), at a latency from the stimulus of 23 to $45 \mathrm{~ms}$ (mean $33.2 \pm 5.6 \mathrm{~ms}$ ). These results are illustrated in fig 2 . A third component was recognised in three recordings, occurring 5 $\mathrm{ms}, 7 \mathrm{~ms}$ and $9.5 \mathrm{~ms}$ respectively after the second component (fig 1).

\section{Discussion}

Clinical testing of the anal reflex is traditionally performed by pricking the perianal skin repetitively, or by dragging a roughly pointed object such as an orange stick across the perianal skin on either side of the anal orifice. These stimuli usually cause a brief contraction of the superficial and deep parts of the anal sphincter, resulting in several rapidly consecutive ripples of contraction in the muscle on the side of the stimulus. Clinical observation thus suggests that the anal reflex consists of several phases of activity in the sphincter muscle. In previous reports of our observations of the latency of the anal reflex following perianal electrical stimulation an early response with a latency of $8.3 \pm 1.7 \mathrm{~ms}$ was recorded. The evidence that this early response is of reflex origin is discussed in our earlier reports. ${ }^{45}$ In dissections of two female cadavers ${ }^{4}$ we found that the length of the pudendal innervation of the external anal sphincter ${ }^{10}$ was 20 and $28 \mathrm{~cm}$ respectively. Chantraine et $\mathrm{al}^{15}$ found that the pudendal conduction was $56 \mathrm{~m} / \mathrm{s}$. These figures give a theoretical value for the anal reflex latency, in women, of 8.6 to $11.5 \mathrm{~ms}$, allowing for a synaptic delay of $1.5 \mathrm{~ms}$. However, direct percutaneous stimulation of the spinal cord in two normal male subjects, reported in this volume by Marsden et al ${ }^{16}$ gave a latency for conduction from L1 to the anal verge of $7 \mathrm{~ms}$. Although this latency is probably shorter in most women because of their smaller stature it is likely

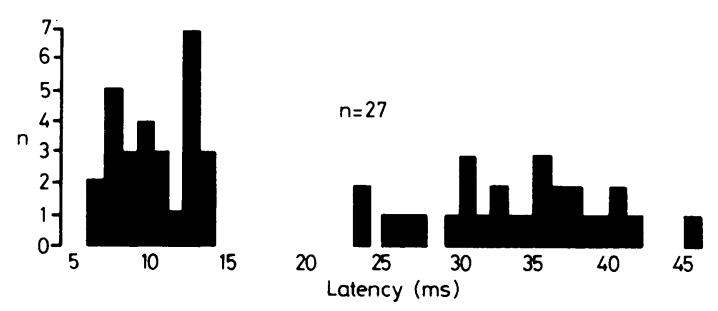

Fig 2 Histogram of latencies of first and second components of the reflex external anal sphincter response to perianal percutaneous electrical stimulation.

that the very short anal reflex latencies recorded in some of our normal subjects, for example, $6.5 \mathrm{~ms}$, are not reflex in origin, but must be due to spread of stimulus current directly to small branches of the pudendal innervation of the external sphincter muscles. The biphasic nature of the histogram of the first component of these latency measurements (fig 2) is consistent with this suggestion, perhaps indicating that only the second peak at 11 to $14 \mathrm{~ms}$ in this first component represents a true reflex response to perianal cutaneous electrical stimulation. The changes we have found in this latency in patients with pelvic floor disorders provide support for our contention that there is a short-latency component of the electrically elicited anal reflex in man, although the method we have used for studying this reflex seems not always to produce a clear reflex response. Indeed, in all our recent work on pelvic floor disorders we have preferred to use single fibre EMG fibre density measurements as a parameter of external anal sphincter function.

Our recent recordings, made using a slow oscilloscope sweep, have revealed a second component at $33.2 \pm 5.6 \mathrm{~ms}$, and sometimes a third component of this reflex response (figs 1 and 2). Pedersen et $l^{11}$ in independent investigations of the anal reflex using a similar electro-physiological technique, found an anal reflex response with a mean latency of $50 \pm$ $10.5 \mathrm{~ms}$ with no earlier component. In these investigations a cut-off relay of 15 to 20 ms duration was employed in the input to the preamplifier, making it impossible for the earlier component of the anal reflex to be identified. Pedersen $e$ al $^{11}$ noted that the latency of the reflex response they recorded varied with different stimulus parameters. Their stimulus, unlike ours, consisted of a train of five square wave pulses each $1 \mathrm{~ms}$ in duration, and each separated by an interval of $1 \mathrm{~ms}$. It seems likely that the second component we have recorded at $33.2 \mathrm{~ms}$ is related to the response recorded by Pedersen et al,${ }^{11}$ the difference in latency being accounted for by the difference in experimental technique. In our recordings, the earlier component was recorded in response to re- 
peated single shock stimuli applied at $1 \mathrm{~s}$ intervals. Our experiments were performed as control studies during our investigations of patients with anorectal incontinence and we have not had opportunity to investigate the possibility that this second component of the anal reflex, presumably representing polysynaptic activity in the anterior horn in the region of Onuf s nucleus, ${ }^{6}$ or the result of ascending relays within the cord, occurs bilaterally as is the case with the second component of the blink reflex. ${ }^{1214}$

Finally, it should be noted that there are other possible ways of investigating the reflex control of the anal sphincter. For example, sudden rectal distension causes cessation of ongoing spontaneous activity in the external sphincter muscle, the rectosphincteric reflex, a phenomenon which accounts, in part, for the patulous anal orifice found in patients with faecal impaction. The latency of this response has not, so far, been determined but might prove a useful investigation in patients with lesions of the sacral cord, cauda equina, or sacral nerve plexus.

This work was generously supported by the St Mark's Hospital Research Fund. I thank Mr MM Henry, Mr ME Neil and Mr J Percy for their help in making the recordings on which this report is based.

\section{References}

' Rossolimo G. Der Anal reflex: Physiologie und Pathologie. Neurol Centralbl 1981;10:257-9.

${ }^{2}$ Beersiek F, Parks AG, Swash M. Pathogenesis of anorectal incontinence; a histometric study of the anal sphincter musculature. J Neurol Sci 1979;42:111-27.

${ }^{3}$ Parks AG. Anorectal incontinence. Proc Roy Soc Med 1975;68:681-90.

${ }^{4}$ Henry MM, Parks, AG, Swash M. The anal reflex in idiopathic faecal incontinence: an electrophysiological study. Brit J Surg 1980;67:781-3.

${ }^{5}$ Henry MM, Swash M. Assessment of pelvic floor disorders and incontinence by electrophysiological recording of the anal reflex. Lancet 1978;1:1290-1.

${ }^{6}$ Mannen T, Iwata M, Toyokura Y, Nagashima K. Preservation of a certain motor neurone group of the sacral cord in amyotrophic lateral sclerosis: its clinical significance. J Neurol Neurosurg Psychiatry 1977;40:464-9.

${ }^{7}$ Parks AG, Swash M, Urich H. Sphincter denervation in ano-rectal incontinence and rectal prolapse. $J$ Neurol Neurosurg Psychiatry 1977;18:656-65.

${ }^{8}$ Neill ME, Parks AG, Swash M. Physiological studies of the pelvic floor musculature in idiopathic faecal incontinence and rectal prolapse. Brit $J$ Surg 1981;68:531-6.

${ }^{9}$ Neill ME, Swash M. Increased motor unit fibre density in the external anal sphincter muscle in ano-rectal incontinence: a single fibre EMG study.J Neurol Neurosurg Psychiatry 1980;43:343-7.

${ }^{10}$ Percy JP, Neill ME, Parks AG, Swash M. Electrophysiological study of motor nerve supply of pelvic floor. Lancet 1981;1:16-7.

$"$ Pedersen E, Harving H, Klemar B, Torring J. Human anal reflexes. J Neurol Neurosurg Psychiatry 1978;41:813-8.

${ }^{12}$ Shahani BT, Young RR. Human orbicularis oculi reflexes. Neurol (Minneap) 1972;22:149-54.

${ }^{13}$ Kinura J. Electrically elicited blink reflex in diagnosis of multiple sclerosis. Brain 1975;98:413-26.

${ }^{14}$ Kimura J, Lyon LW. Obicularis oculi reflex in the Wallenberg syndrome: alteration of the late reflex by lesions of the spinal tract and nucleus of the trigeminal nerve. J Neurol Neurosurg Psychiatry 1972;35:22833.

${ }^{15}$ Chantraine A, De Leval J, Onkelinx A. Motor conduction velocity in the internal pudendal nerves. In: Desmedt JE (ed). New Developments in Electromyography and Clinical Neurophysiology vol 2. Basle: Karger, 1973:433-8.

${ }^{16}$ Marsden CD, Merton PA, Morton HB. The latency of the anal reflex.J Neurol Neurosurg Psychiatry 1982;45:857. 